\title{
Anatomy in the Susruta Samhita
}

\author{
${ }^{1}$ Subhajyoti Borgohain \& ${ }^{2}$ Bini Saikia \\ ${ }^{1,2}$ Research Scholar Sanskrit Department Gauhati University.
}

\begin{abstract}
Ayurveda is the Indian system of traditional medicine. It is attributed to Dhanvantari, the physician to the gods in Hindu Mythology, who received it from Brahma. The most important Ayurvedic are the Caraka Samhita and Susruta Samhita.

Susruta Samhita is attributed to Susruta. He was the $1^{\text {st }}$ Indian surgeon of 600 century BC. The Susruta Samhita is a Sanskrit text on surgery. It is the main source of knowledge about surgery in ancient India. The Susruta Samhita provided important surgical and anatomical information of the understanding of anatomy by Indians in the $6^{\text {th }}$ century BCE. Anatomical knowledge in ancient India was derived principally from animal sacrifice, chance observations of improperly buried human bodies and examinations of patients made by doctors during treatment.

It was Susruta's belief that for one to be a skilful and erudite surgeon, one must first be an anatomist. The Susruta Samhita is made up of 10 chapters regarding the study of human anatomy. According to Susruta Samhita, the different parts or members of the body as mentioned before including the skin, cannot be correctly described by one who is not well versed in anatomy. In this present paper an attempt has been made to highlight the anatomy as depicted in the Susruta Samhita.
\end{abstract}

\section{Introduction}

Ayurveda, 'the knowledge for or science of life,' is the Indian system of traditional medicine. The most important Ayurvedic texts are the Caraka Samhita and Susruta Samhita. The Susruta Samhita is a Sanskrit text on surgery. It is the main source of knowledge about surgery in ancient India. It is attributed to Susruta. He was the first Indian surgeon of 600 century BC.

The Susruta Samhita provided important surgical and anatomical information of the understanding of anatomy by Indians in $6^{\text {th }}$ century BCE. Susruta beliefs that for one to be a skilful and erudite surgeon, one must first be an anatomist. The Sarira Sthana of the Susruta Samhita is made up of ten chapters regarding the study of human anatomy. In ancient India anatomical knowledge was derived principally from anatomical sacrifice, chance of observations of improperly buried human bodies and examinations of patients made by the doctors during treatment.

The need to know the structure of the body in the Indian system of medicine, was felt mainly for the performance of surgical operations. But even for this, knowledge of the anatomy of the whole of the body was not considered essential. Because, it was enough if one knows which particular spot a region of the body should not be cut with a lancet, otherwise it would give rise to either excessive bleeding leading to death, or to loss of some particular function or disability. Knowledge of such sensitive spot (marma) was gathered through practical experience of operating upon patients requiring surgical interference. Indian surgeons had gathered an extensive knowledge about such sensitive spots or regions and this is stated in great detail in Susruta Samhita. ${ }^{1}$

\section{The text of Susruta Samhita:}

The Susruta Samhita refers to the eight branches of Ayurvedic medicine. It is divided into six sections and 184 chapters. Susruta describes the need for and way to conduct dissections on human cadavers to gain knowledge of anatomy. Quartered sacrificial animals were used to study different kinds of anatomy. It describes more than 300kinds of operations that call for 42 different surgical processes and 121 different types of instruments.

\section{Anatomy in the Susruta Samhita:}

A fully developed foetus with all its parts, such as the hands, feet, tongue, nose, ears, buttocks etc. and the sense- organs, is called sariram or body. ${ }^{2}$ The body is composed of six main parts, viz. the four extremities (upper and lower), the trunk or middle body and the head.

\section{Different members of the body:}

Susruta describes the Pratyangas or members of the body. According to Susruta Samhita the members of the body are- the head, the belly, the back, the naval(umbilical region), the forehead, the nose, the chin, the bladder, the throat, the ears, the nostrils, the eye brows, the temples, the shoulders, the cheek, the armpits, the 
breasts, the testes, the sides, the buttocks, the arms, the thighs, and the knee-joints etc. ${ }^{3}$ The fingers and toes, twenty in number and the interior channels of the body are also included within the Pratyangas in the Susruta Samhita.

Moreover, there are different members of the body such as the different layers of the Skin, the Kalas, the Datus, the Mala, the Doshas, the Spleen, the Liver, the Lungs, the Colon and Coecum (unduka), the Heart, the Cavities or Viscera, the Intestines, the Vrikkau, the Scrotas, the Kandara, the Jalas, the Kurchas, the Rajjus, the Sevanis, the Sanghatas, the Simanta, the Bones, the Joints, the Snayu, the Pasi, the Marmas, the Sira, the Dhamani and the Yogavahini Srotas. All these members, according to Susruta Samhita are collectively called as organism. ${ }^{4}$ Again all of them have several members. For example, as describes in the Susruta Samhita the layers of skin is seven in number, the Dhatu of the body are seven in number, there are seven hundred Sira, five hundred Pesi, nine hundred Snayu, three hundred Bones etc. ${ }^{5}$

\section{Regional anatomy in the Susruta Samhita:}

In the Susruta Samhita, one hundred and seven Marmas have been described on the whole of the human body. ${ }^{6}$ The effect of injury to each one of the Marmas gives an idea of the regional anatomy to the Indian surgeons.

Marmas are the meeting place of any two or more of the five elements of the body. The five elements are- vessels, muscles, ligaments, bones and joints. Marmas are classified into five groups. They are-mansamarmas(flesy), sira-marmas, snayu-marmas, asthi-marmas and the sandhi-marmas. ${ }^{7}$ Among them there are eleven mansa marmas, forty one sira marmas, twenty seven snayu marmas, eight asthi marmas and twenty sandhi marmas. ${ }^{8}$ They are situated eleven in each limb, making a total of 44; 12 in the region of the chest and abdomen; 14 in the back; 37 in the neck and above it. ${ }^{9}$

According to the effect of injury to them, Marmas are divided into five categories- sadya-pranadhara, fatal result within 24 hours; kalantra pranadhara, fatal result within a fortnight or a month; visalyaghna, fatal as soon as dart or any other embedded body is extracted from them; vaikalyakara, causing deformity, and rujakara, causing pain. ${ }^{10}$

Particular category of Marmas has a particular effect after injury due to its particular constitution. In this context Susruta Samhita states that Marmas belonging to sadya pranadhara are possessed of fiery virtues easily enfeebled if injured. So they prove fatal soon. Those belonging to the kalantara pranahara group are fiery and lunar in their properties, and as the fiery virtues are enfeebled easily and the cooling ones take a considerable time, so the Marmas of this group, if hurt, prove fatal after a longer time. The vialyaghma marmas are possessed of vataya properties, that is, they arrest the escape of the vital vayu so that as long as the dart does not allow the vayu to escape from their injured interior, the life continues; but as soon as the dart is extricated, the vayu escapes from insides of Marmas and then the injury proves fatal. The vaikalyakara marmas are possessed of lunar properties and they retain the vital fluid owing to their steady and cooling virtues, and hence tend only to deform the organism in the event of their being hurt. The rujakara marmas of fiery, and vataja properties become extremely painful in as much as both of them are pain-generating in their properties. ${ }^{11}$

According to Susruta Samhita, the four classes of vessels, which respectively carry the vayu, pitta, kapha and the blood, are found to enter into the Marmas for the purpose of keeping or maintaining the moisture of the local ligaments, bones, muscles and joints and thus sustain the organism. ${ }^{12}$

Again Susruta gives a detailed description of some of the important Marmas according to their region. Marma, known as the kshipra is situated in the region between the first and the second toes. When this is injured or pierced, it causes death from convulsions. A perforation of the Gulpha Marma situated at the junction of the foot and the calf, results in pain, paralysis and lameness of the effected leg. An injury to the Indravasti Marma which is situated in the middle muscle of the calf at a distance of twelve to thirteen fingers from the ankle, results in excessive haemorrhage causing death. An injury to or piercing of the Janu Marma situated at the union of the thigh and the knee causes lameness. An injury to the Vitapa Marma situated between the scrotum and the inguinal region causes impotency. ${ }^{13}$ Of the Marmas in the thorax and abdomen, an injury to the Guda Marma which is attached to the large intestine and serves as the passes for stool and flatus, ends fatally within twenty four hours of the injury. An injury to the Vasti Marma present inside the pelvic cavity near the urinary bladder proves fatal within the day as the urine oozes out through the aperture when one of its walls is perforated. This, however, may be closed and healed up with proper and judicious treatment. An injury to the Nabhi Marma, the root of all the Siras, and situated between the amasaya(stomach), and the pakvasaya (intestines) ends in death within the day. An injury to the Hridaya Marma which is situated in the thorax between the two breasts and above the pit of the amasaya proves fatal within the day. An injury to the Snana-Mula Marmas situated immediately below each of the breasts and about two fingers in width, fills the thorax with deranged kapha, brings on cough, difficult breathing and proves fatal. An injury to any of the Stana-Rohita Marmas, situated above the nipples of the breasts about two fingers in width, fills the cavity of the thorax with blood, producing symptoms of cough and asthma, and ends fatally. An injury to the Apalapa Marmas situated below the axilla, 
transforms the blood of the organism into pus and proves fatal thereby. An injury to any of the vayu carrying vessels, known as the Apastamba Marma fills the thorax with the deranged vayu, leading to cough, dyspepsia and death. ${ }^{14}$ Susruta Samhita again discusses about the Marmas in the back of a man. It states that an injury to any of the Katika-Tarunas situated in the region of sroni on both of the spinal column, gives rise to an excessive haemorrhage and consequent pallor and death. An injury to any of the Kukundara Marmas, situated on both sides of the spinal column, results in complete anaesthesia and loss of function of the lower extremities. An injury to the Nitamva Marmas attached to the side above the sroni and inside to the muscles of the waists, causes sosha of the lower extremities. An injury to the Parshvasandhi Marma fills the abdomen with blood and results in death. An injury to the Vrihati Marmas which commencing from the roots of the breasts, course round both sides of the spinal column, cause excessive bleeding and death. An injury to any of the two Amsa Phalaka Marmas situated on either side of the vertebral column and connected with the scapula causes anaesthesia or atrophy of the arms. An injury to any of the two Amsa Marmas, which are situated on either side midway between the neck and the top of the arms, is attended with incapacity to move the hands. ${ }^{15}$

After the Marmas situated in the back, Susruta Samhita describes the Marmas which are situated in the regions above the clavicles. It states that an injury to any of the two Sira-Matrika Marmas consisting of four vessels on the two sides of the neck, causes death within a day. An injury to any of the two Krikatika Marmas lying at the junction of the head and neck results in a free movement of the head. An injury to any of the Vidhura Marmas attached to the lower end of an ear results loss of hearing. An injury to the Phana Marmas attached to the interior channels of both the nostrils, results in the loss of the faculty of smell. An injury to the Apanga Marmas situated below the tips of the eye-brows and about the external corners of the eyes causes blindness or impaired vision. An injury to the Sankha Marmas situated over the tips of the eye-brows and between the ears and the forehead, results in within the day. The Utkshepa Marmas situated over the two temples near the place where the hair end, when injured by the shaft of an arrow and that shaft is extracted, results in the death of the patient; if, on the contrary, the shaft is allowed to remain inside or if the shaft comes out of its own accord (after putrefaction), the patient survives. An injury to the Staphani Marma, situated in the middle of the eye-brows, ends in a manner similar to the proceeding one. An injury to any of the five joints of the head known as the Simanta Marmas results in madness. An injury to any of the four Sringataka Marmas which forms the junction of the four Siras and soothes the nose, the eyes, the ears and the tongue, proves fatal within the day. An injury to the Adhipati Marmas which is marked on the inner side of the roof of the cranium by the Sira sannipata and on the external side by the ringlet of the hair, proves fatal within the day. ${ }^{16}$

Susruta Samhita gives precise measurement of the distances around the Marmas within which a lancet should not be used. A major injury away from a Marma is less dangerous than a minor injury near or upon a Marma.

\section{General body anatomy}

According to Susruta Samhita, any one desirous of acquiring a thorough knowledge of anatomy should prepare a dead body and carefully observe by dissecting it and examine its different parts. Moreover, it states that a dead body selected for this purpose should be complete in all its parts. It should also be the body of a person who was not excessively old, nor of a person who died of poisoning or of a protected disease. After removing all the filthy matter from the intestines, the body should be wrapped in grass and then put in a cage. This should then be deposited at a secure and hidden spot in a river and the body allowed to decompose. After an interval of seven days, the thoroughly decomposed body should take out and very slowly scrubbed with a whisk made of grass roots. At the same time, every part of the body, great or small, external or internal, beginning with the skin should be examined with the eye, one after the other as it becomes disclosed in the course of the process of scrubbing. ${ }^{17}$

Susruta Samhita also describes the rectum, the uterus and the unitary bladder. This description of rectum etc. shows that anatomy of that part of the body which came frequently under observation because of surgical operations or other man oeuvres was well known. The rectum came under observation for giving enema, vagina, and uterus in cases of delivery, and the unitary bladder for the removal of stones.

Moreover, Susruta Samhita describes embryology in great detail. In this context it describes the gradual development of the embryo. ${ }^{18}$ It also describes the process of formation of different organs of the body. Susruta says-different organs of the body are formed from the blood; some out of its essential and others out of its non-essential parts, by the action of heat of the pitta. The spleen and the liver are formed out of the blood; the lungs are formed out of the froth of the blood; the unduka from the dirk of the blood. The intestines, bladder and rectum are formed out of the essence of blood and kapha. The kidneys are formed out of the essence of blood and fat. The tests are formed out of essence of blood, flesh, kapha and fat. The heart is formed out of the essence of blood and kapha.

\section{Conclusion}


Thus Susruta Samhita gives detail knowledge of the Marmas, the anatomical knowledge which helps the ancient Indian surgeons to perform operations, some of which till modern times were considered nothing less than miracles.

\section{References:}

[1]. O.P. Jaggi: History of Science and Technology in India, vol iv. Indian System of Medicine, p.89.

[2]. Susruta Samhita. 3.5. 1

[3]. ibid. 3.5.3

[4]. ibid. 3. 5.4

[5]. ibid. 3. 5. 5-17

[6]. ibid. 3.6.2

[7]. ibid

[8]. ibid. 3.6.3

[9]. ibid. 3.6.4

[10]. ibid. 3. 6.16-21

[11]. ibid. 3. 6. 23

[12]. ibid. 3. 6. 26-29

[13]. ibid. 3. 6. 32-42

[14]. ibid. 3. 6. 47-56

[15]. ibid. 3. 6. 57-64

[16]. ibid. 3. 6. 65-80

[17]. ibid. 3. 5. 50-56

[18]. ibid. 3. 3. 14-16 